\title{
COVID 19, CAPITALISMO E EXCLUSÃO SOCIAL NA COMUNIDADE QUILOMBOLA
}

\author{
Cynthia Maria Bindá Leite ${ }^{8}$ \\ Heloísa Helena Corrêa da Silva ${ }^{9}$
}

\begin{abstract}
RESUMO
Este estudo é um recorte de pesquisa de Doutorado, em andamento, cujo tema é inclusão e exclusão social na comunidade quilombola Sagrado Coração de Jesus, Lago de Serpa, Itacoatiara/Am e que tem como foco principal, pensar as consequências da pandemia do Coronavírus - Covid 19 para a comunidade quilombola, por meio de uma consciência crítica diante da exclusão social pela ideologia de raça, isolamento social e sobrevivência num cenário alarmante de racismo estrutural. Para tal, realizou-se pesquisa bibliográfica, além de entrevistas semi-estruturadas com os diversos agentes envolvidos no conflito. A percepção geral é a de que os negros sofrem ainda mais na pandemia pelo Covid 19 pelo racismo estruturante como consequência do capitalismo vigente, não acidental, pelo momento da pandemia, mas, como característica da exclusão social histórica e enraizada na nação brasileira
\end{abstract}

Palavras chave: Comunidade quilombola, Pandemia, Covid 19, Capitalismo

\section{COVID 19, CAPITALISM AND SOCIAL EXCLUSION IN THE QUILOMBOLA COMMUNITY}

\begin{abstract}
His study is an excerpt of ongoing $\mathrm{PhD}$ research, whose theme is inclusion and social exclusion in the quilombola community Sagrado Coração de Jesus, Lago de Serpa, Itacoatiara/Am and whose main focus is to think about the consequences of the Coronavirus pandemic - Covid 19 for the quilombola community, through a critical awareness of social exclusion by the ideology of race, social isolation and survival in an alarming scenario of structural racism. To this end, bibliographical research was conducted, in addition to semi-structured interviews with the various agents involved in the conflict. The general perception is that blacks suffer even more in the pandemic by Covid 19 by structuring racism as a consequence of the prevailing capitalism, not accidental, by the moment of the pandemic, but as a characteristic of historical social exclusion and rooted in the Brazilian nation.
\end{abstract}

Keywords: Quilombola community, Pandemic, Covid 19, Capitalism

\footnotetext{
8 A pesquisadora é Doutoranda do Programa de Pós Graduação em Sociedade e Cultura da Amazônia (UFAM), Mestre em Educação pela Universidade Federal do Amazonas (UFAM). Orientadora: Heloísa Helena Corrêa da Silva Professora doutora em Serviço Social pela Pontifícia Universidade Católica de São Paulo - PUC-SP, Brasil (2001) Professor Associado 4Classe D do Departamento de Serviço Social da Universidade Federal do Amazonas - UFAM e do Programa de Pós Graduação Sociedade e Cultura na Amazônia - PPGSCA. Líder do Grupo de Pesquisa Questão Social e Serviço Social no estado do Amazonas. Certificado pelo Conselho Nacional de Pesquisa - CNPq.

${ }^{9}$ Possui graduação, mestrado, doutorado e pós-doutorado em Serviço Social pela Pontífice Universidade Católica de São Paulo - PUC-SP, pesquisadora do Núcleo de Estudos e Pesquisas sobre Seguridade Social e Assistência NEPSAS/PUC-SP, membro do GT- Indígenas em Contexto Urbano do CLACSO e pesquisadora da Rede PRINQUI. ORCID: https://orcid.org/0000-0002-0777-5808.
}

CV Lattes: http://lattes.cnpq.br/4664295271962137. 


\section{INTRODUÇÃO}

Este artigo tem por objetivo pensar as consequências da pandemia do Coronavírus - Covid 19, contribuindo para a reflexão sobre o ser negro no cenário da pandemia Covid-19 sob a égide do sistema capitalista vigente tendo como consequência a exclusão social, considerando a exigência de isolamento social sem as mínimas condições necessárias e o racismo estrutural por meio do sistema político econômico. Diante da insegurança e falta de perspectiva e definições sobre o futuro, o sistema capitalista, surge no início da Idade Moderna com a industrialização e ascensão da burguesia. Marx (1984) e Engels (2010), em Ideologia alemã, destaca a importância das condições materiais para a produção e reprodução dos modos de sobrevivência. $\mathrm{O}$ negro no cenário pandêmico sofre exclusão que refletem às questões históricas, pelas disparidades sociais produzidas que reduzem o valor do ser humano às questões raciais.

Cabe destacar nesta breve introdução que o termo "raça", durante muito tempo, caracterizou a finalidade de evidenciar a noção de supremacia racial por meio do racismo, cuja função social é a exclusão pela cor, como é evocado pelos autores que serão referenciados neste artigo e corroborando com a ideia, outro autor, provoca a reflexão sobre os conceitos de racismo como ícone das relações sociais, registrando que todo racismo é estrutural e cumpre o papel avassalador do capitalismo possui raízes históricas, culturais e interpessoais, dentro de uma sociedade que frequentemente elege um grupo social ou étnico em detrimento de outro. Quanto a crise sanitária gerada pela pandemia covid 19, a Organização Mundial de Saúde (OMS) concebeu o racismo como um dos determinantes sociais do processo de adoecimento e morte do negro.

\section{METODOLOGIA}

Este recorte de pesquisa foi desenvolvida no âmbito do Programa de Pós-Graduação em Sociedade e Cultura da Amazônia ${ }^{2}$, na linha de pesquisa 3. Tem como lócus de pesquisa Comunidade Quilombola Sagrado Coração de Jesus, Lago de Serpa, Itacoatiara/AM.

Optou-se por uma pesquisa-ação, conforme Hunges Dionne (2007), porque implica em atender a dois objetivos específicos e simultâneos: cumprir uma tarefa de pesquisa cujo objetivo é desenvolver e sistematizar um conhecimento e, ao mesmo tempo, desdobrar uma tarefa de ação que tem por escopo modificar uma situação em particular.

A pesquisa se configura como etnográfica, portanto qualitativa, e utiliza as técnicas de revisão bibliográfica e acesso ao Sistema de Notificações da Covid 19 das secretarias dos estados, disponibilizados nas mídias e do Ministério da Saúde. Envolveu 3 (três) sujeitos da comunidade, dentre os quais, o líder da associação comunitária quilombola.

A pergunta norteadora foi: Como descrever as principais dificuldades encontradas por você e sua família frente ao cenário da pandemia covid 19 ?.

Os resultados evidenciam lacunas deixadas pelo poder público nas questões raciais na luta por seus direitos em todas as áreas e em especial na área da saúde

\subsection{PANDEMIA COVID 19 E O RACISMO ESTRUTURAL}


As desigualdades sociais foram divisores estatísticos na representatividade da pandemia entre remanescentes de quilombos em Itacoatiara/AM. Na Comunidade Sagrado Coração de Jesus, Lago de Serpa, constava que nenhum quilombola havia contraído o coronavírus. Em visita in loco no mês de julho /2020, para observação sistemática e procedimentos de entrevistas para a pesquisa de doutorado e em conversa com o presidente da Associação Quilombola da Comunidade, constatou-se que havia 9 (nove) casos de contaminação e 1 (uma) morte.

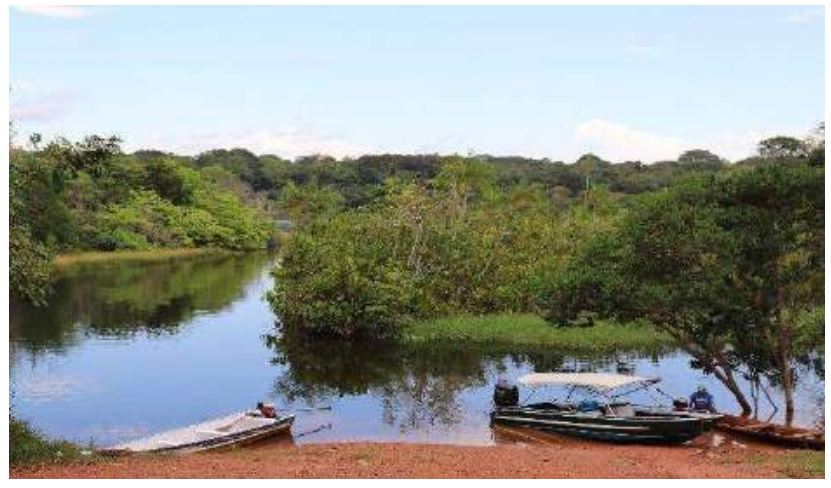

Foto do acervo pessoal da pesquisadora Leite, Cynthia M B em 17/07/2020.

Lago de Serpa- Itacoatiara/Am

A invisibilidade dos negros da Comunidade quilombola do Lago de Serpa é causada pelos diversos rebatimentos que o modo de produção capitalista provoca quando não oferece espaço e políticas públicas para o conjunto da população, o que deixa perceptível a ação de exclusão através do racismo e induz esta pesquisadora a inquietação de como explicar o porquê desse fato ocorrer no Estado do Amazonas, que foi precursor na eliminação das relações escravistas de produção.

O locus da pesquisa que se situa no município de Itacoatiara distante apenas 176 quilômetros de Manaus, não justifica o fato da ausência de um acompanhamento eficaz em período de pandemia e nem ao menos não constar nos registros oficiais a morte no quilombo. Isso só cabe explicação no viés do racismo estrutural ${ }^{10}$, tomando-se como exemplo a declaração do pesquisador da Secretaria de Saúde do Estado de São Paulo, Luís Eduardo Batista "Entendemos que o racismo está estruturado na nossa sociedade, e por isso impacta a vida de todos de diferentes formas. Ele interfere no acesso aos serviços, na qualidade e até nas relações do usuário com o profissional"

A luta por representatividade negra nos boletins, relatórios e espaços antes específicos para os brancos, denuncia o racismo estrutural. Contudo, não representa inclusão dos negros nesses documentos e locais, "é uma falácia" (ALMEIDA, 2018, p.25) uma farsa utilizada para minimizar as reações do movimento negro. $O$ autor afirma ainda que o racismo está institucionalizado historicamente e os estudos a respeito da desigualdade racial existem para justificar a inferioridade negra e que não há preocupação real com a condição do negro na sociedade.

10TEIXEIRA, 2015 conceitua o racismo estrutural como o responsável pela desigualdade social entre sujeitos negros e brancos. 
Racismo "é uma forma sistemática de discriminação que tem a raça como fundamento, e que se manifesta por meio de práticas conscientes ou inconscientes que culminam em desvantagens ou privilégios, a depender ao grupo racial ao qual pertençam"

(ALMEIDA, 2018, p. 25)

Para o autor, a institucionalização do racismo está ligada ao imaginário nacional brasileiro, sua concepção é carente do histórico reflexivo sobre os seus efeitos reais. (ALMEIDA, 2018). Contudo, o mais grave é considerar que "evoluíram a partir da miscigenação com brancos ou tiveram contato com estes" e que alguns pesquisadores afirmem que "os negros americanos são mais evoluídos que os africanos porque tiveram mais contato com os brancos" (MBEMBE, 2014, p.56-58). Por razões semelhantes e piores que essas, os movimentos negros estão ainda de forma ainda parcial, em pleno processo revolucionário, gritando por seus direitos, como exemplo, a pergunta que continua sem resposta, quem mandou matar Marielle Franco?

Em nível de reflexão, no Brasil, somente depois de 130 anos após a assinatura da Lei Áurea, os negros obtiveram as primeiras nuances de liberdade (FERNANDES, 1978). Os escravos traficados, em sua maioria, eram mantidos em condições subumanas de trabalho, sem remuneração e debaixo de açoite, sem nenhum direito garantido, conforme a literatura sobre a temática da escravidão no Brasil (AZEVEDO, 1987; FERNANDES,1965). O que lhes restava era ficar nas fazendas em que trabalhavam ou o trabalho pesado e informal.

Nos dias atuais, o cenário não é muito diferente, as tarefas mais árduas, as piores remunerações e as formas mais cruéis de invisibilidade social ainda são reservadas às pessoas de cor preta e conforme o Instituto Brasileiro de Geografia e Estatística (IBGE, 2018), os prejuízos financeiros e de saúde causados pela covid-19 pesam muito mais sobre mulheres, negros e pobres.

A pandemia pelo coronavírus desmascarou o racismo estrutural em vários países ao expor profundas desigualdades sociais. No caso do Brasil, o racismo além de estrutural é sistematizado desde o escravismo colonial (WERNECK,2016) e o assunto veio denunciar o estigma social que a população negra recebeu ao longo dos anos.

No Estado e nas leis que alimentam a exclusão da população negra, se materializam, por exemplo, na ausência de políticas públicas que possam promover melhores condições de vida a essa população. As questões raciais são estruturantes porque fazem parte da construção da nossa sociedade, estão em todos os locais e em todos os momentos. Está presente nas subjetividades que as compõe. 


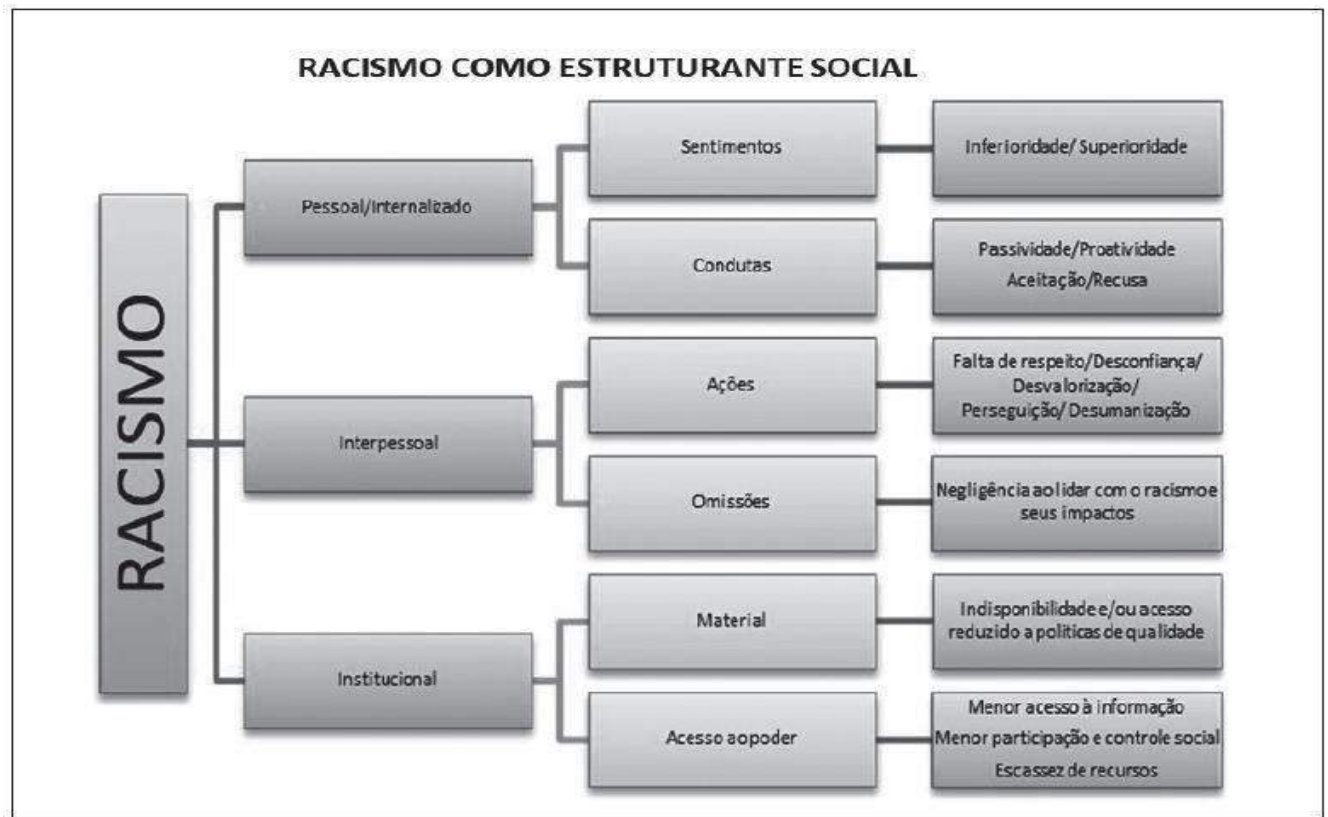

Fonte: Racismo Institucional e Saúde da População Negra (Werneck, 2016, p.542). Figura 2 Dimensões do Racismo, 2013. Baseado no modelo proposto por Jones (2002).

O fenômeno que ocorre nos quilombos, em geral, demonstra a exclusão social do negro e isso é exposto claramente através da pandemia pelo Covid 19, na ausência de assistência médica, pelos meios de comunicação precários, invisibilidade das comunidades quilombolas:

Estamos falando de um grupo que carrega dificuldades estruturais no seu viver, provocada por um racismo estrutural e estruturante, que começa desde a informação que chega a essa população até o acesso a exames para detecção do vírus, principalmente no que chamamos de casos suspeitos.

(ALTAIR LIRA, professor do Instituto de Humanidades, Artes e Ciências da UFBA (IHAC/UFBA) e integrante do Grupo Temático Racismo e Saúde (GT Racismo/Abrasco)

Sem a devida assistência pelo poder público em período de pandemia às comunidades quilombolas, de acordo com informação do Instituto socioambiental, foi necessário o esforço dos próprios líderes das comunidades, que criaram redes de informação sobre o avanço da doença em todas as regiões do país e prestaram as informações aos principais meios de comunicação.

As relações pessoal, interpessoal e institucional estão impregnadas numa construção histórica equivocada (WERNECK,2016), que faz parte de uma aliança capitalista e marca o Brasil como país racista e excludente, a exemplo disso, no Brasil, 75\% dos mais pobres são negros, conforme declara o levantamento realizado em 2018 pelo Instituto Brasileiro de Geografia e Estatística (IBGE), onde afirma também que os pretos ou pardo estão relacionados aos que recebem menos que os brancos no país. Isso talvez seja uma das explicações para o descaso com as comunidades de remanescentes de quilombos. 


\subsection{CAPITALISMO, ISOLAMENTO SOCIAL E SOBREVIVÊNCIA}

O capitalismo traz desigualdade social como seu ponto forte tendo como suas vítimas principais os mais pobres, as comunidades tradicionais que, além de não ter como sobreviver dignamente ainda trazem as mazelas de um passado de exclusão social. Essas comunidades precisam saber lutar com o inimigo invisível, o Covid-19, e o visível, o sistema econômico opressor, que minimiza a realidade, para não socorrer as classes oprimidas na tentativa de aliená-las.

Durante o período pandêmico foi decretado isolamento social, contudo, em algumas comunidades, não houve como cumprir a determinação municipal pelo perfil social dos moradores do quilombo do lago de Serpa, Itacoatiara/AM, diferente dos habitantes da própria cidade de Itacoatiara, necessitam vender seus produtos, são vendedores autônomos, não possuem acesso à internet e a grande maioria depende das atividades conjunta da própria comunidade. "São pessoas mais vulneráveis porque dependem do seu trabalho autônomo e não podem ficar em casa, contudo, apesar dos riscos, necessitam sobreviver". É o que afirma o professor Altair Lira:

Nesse contexto há necessidade de refletir sobre o peso do capitalismo na comunidade quilombola, pois ele se apresenta por meio do seu real significado, criando leis através do Estado, para garantir o bem estar da burguesia, o acúmulo de capital e assim contribui para a desigualdade social. O enfrentamento à pandemia da Covid-19, expõe as comunidades quilombolas como vítimas do capitalismo vigente.

O descaso das autoridades públicas tem desmascarado a desigualdade social e demonstrado a situação do quilombola para sobreviver e se manter longe da contaminação do vírus, num cenário "de miserabilidade, de privação de direitos, de moradia e de emprego formal" é o que afirma a epidemiologista e uma das coordenadoras do GT Racismo e Saúde da Abrasco e docente da Universidade Estadual de Feira de Santana (UEFS), Edna Araújo. A professora ressalta ainda, que essa negação de direitos é vivenciada rotineiramente principalmente pelos negros e negras do país.

Se as desigualdades sociais já são relevantes em todo Brasil, para o quilombo do lago de Serpa, Itacoatiara/AM, em tempo de pandemia, o cenário fica mais complexo para quem depende de transporte público. O depoimento de um dos membros da comunidade deixa claro a dificuldade de isolamento social "continuamos pegando ônibus, não temos como fazer a quarentena, quando os ônibus pararam não conseguimos vender nada e passamos necessidades. Temos que correr o risco" (RSMM membro da comunidade quilombola).

Os quilombolas receberam orientação para ficar em casa e evitar o contágio e se houvesse algum familiar suspeita da doença (orientação dada a toda população), viabilizassem o isolamento dentro de sua própria casa. Ocorre que alguns membros da comunidade possuem casas muito pequenas, dificultando esse tipo de ação, "meu barraco possui três metros quadrados, somos 10 pessoas porque moram com a gente os meus pais e os pais dela" (JCK membro da comunidade mas que ainda não se declara quilombola). Há necessidade que se priorize estratégias de contenção da Covid-19 nas comunidades quilombolas sem desrespeito as suas culturas. 


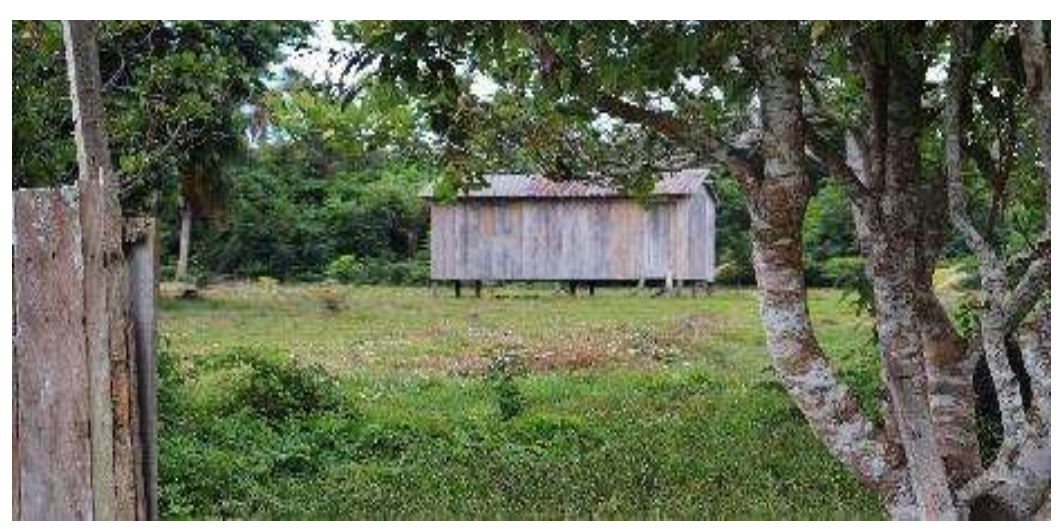

Foto do acervo pessoal da pesquisadora em 17/07/2020

Um dos modelos de moradia do quilombo do lago de Serpa Itacoatiara/Am

Outro fator relevante diante da pandemia provocada pelo coronavírus (SARS2- CoV2) é o aumento da vulnerabilidade dos quilombolas que os inclui no grupo de risco pelas comorbidades específicas comuns a raça negra, como os casos de hipertensão e da diabetes e, principalmente, a anemia falciforme. Nesse aspecto, os membros da comunidade quilombola sentiram dificuldades na continuidade de seus tratamentos específicos, por não ter acesso as tecnologias para consultas virtuais e pela suspensão dos serviços presencias na área de saúde e isso faz parte do cenário devastador do capitalismo vigente.

As autoridades públicas propagam que os negros não estão excluídos do sistema e que isso faz parte de um passado longínquo. Alguns cidadãos quilombolas não enxergam a exclusão social vigente, contudo, o ato de ver vai além de enxergar, Rubem Alves (2015) afirma que já enxergam conseguem ver. Jesus se opôs ao sistema dominante imposto pelas autoridades da época que lucrava com a alienação de um povo (Lc 6,39). O Brasil precisa ver os negros como todo cidadão, possuidor de direitos iguais, intrínsecos a todo ser humano.

\subsection{EXCLUSÃO SOCIAL PELA IDEOLOGIA DE RAÇA}

Do período pós-guerra até os anos 1970, questões como moradia, emprego e estilo de vida eram classificadas como enfermidade, anormalidade ou amoralidade. Destaca-se aqui a situação de grupos vulneráveis, os que foram colocados de lado porque eram loucos, pobres, negros, homossexuais, ladrões ou tarados, cujo dever era adaptar-se às normas da sociedade, conforme afirma Paugam (1996), por esse motivo, eram colocados a margem da sociedade a fim de adaptar-se ao meio imposto pela sociedade. Até adaptar-se eram inexistentes para sociedade. 
O fato do ministério da Saúde não identificar nas estatísticas iniciais de infectados e mortos pelo Covid 19, o gênero e a cor das vítimas, denuncia o descaso das autoridades com as classes de baixa renda, pois comprovadamente, mulheres e negros estão entre os que tem os salários mais baixos. Mesmo antes da Covid 19, era notória a invisibilidade da população negra para o poder público especificamente das comunidades quilombolas, no entanto, com maiores consequências durante a pandemia.

Pela ausência de dados do Ministério da Saúde, no Brasil, que representasse o número de negros acometidos do vírus, foi inevitável a reinvindicação da Coalizão Negra, um grupo de 150 entidades, apresentou uma carta ao Ministério da Saúde e às secretarias de saúde de todos os estados, exigindo a divulgação da cor, do gênero e dos bairro dos infectados, contudo, somente após o dia 11 de abril, quase um mês e meio depois da confirmação do primeiro caso de Covid-19, a reinvindicação foi atendida.

Os conflitos em torno da identificação da população negra giram em torno da ideologia dominante acerca do conceito de raça ligada diretamente com a cor, o que gera dificuldade de identificação étnico-racial. Kabengele Munanga (2003) esclarece que o conceito de raça como empregamos, está carregado de ideologias, e inexiste o biológico, está intrínseca a relação de poder e de dominação.

Diante da complexidade da discussão sobre etnia e raça, Jacques D’Adesky (2001) ressalta quão difícil é apreender o conceito das categorias de análise. No entanto, é importante considerar a operacionalidade na vida social das categorias raciais (ou de cor).

No Brasil, podemos verificar que o conceito de raça estabelece uma relação direta com a cor o que ocasiona conflitos em torno da identificação da população, gerando com isso, a dificuldade da afirmação identitária étnico-racial Kabengele Munanga (2003). O autor destaca ainda que etnia é um conjunto de indivíduos que, histórica ou mitologicamente, têm um ancestral e uma língua em comum, uma mesma religião ou cosmovisão, uma mesma cultura e moram num mesmo território. Guimarães (2003) ressalta que cor não é uma categoria objetiva mas racial, trata-se de um conceito social.

"Cor" não é uma categoria objetiva, cor é uma categoria racial, pois quando se classificam as pessoas como negros, mulatos ou pardos é a ideia de raça que orienta essa forma de classificação. Se pensarmos em "raça" como uma categoria que expressa um modo de classificação baseado na ideia de raça, podemos afirmar que estamos tratando de um conceito sociológico, certamente não realista, no sentido ontológico, pois não reflete algo existente no mundo real, mas um conceito analítico nominalista, no sentido 
de que se refere a algo que orienta e ordena o discurso sobre a vida social (GUIMARÃES, 2003, p.103-104)

De acordo com a pesquisa do IBGE (2018), 39\% dos trabalhadores pretos e pardos estão em regime de informalidade, ante $29,9 \%$ dos brancos. Autônomos e informais foram justamente os que mais perderam renda na crise. "São trabalhadores atingidos duplamente", afirma o economista Sandro Sacchet, do Instituto de Pesquisa Econômica Aplicada (Ipea). Os dados do IBGE (2018) demonstram que há uma morte para cada três brasileiros negros hospitalizados por Covid-19, enquanto entre brancos a proporção é de uma morte a cada 4,4 internações. Em São Paulo, cidade com o maior número de casos de covid 19, bairros com maior concentração de negros têm mais óbitos pela doença. Dos dez estados com o maior número absoluto de mortes por coronavírus, oito têm mais negros que a média geral.

Os pretos ou pardos, estão listados entre os que mais tem probabilidades de contrair o vírus Covid 19, de acordo com o IBGE (2018), 68,3\% declararam ter tido mais de um sintoma de síndrome respiratória, ante apenas 30,3\% de brancos. Ruy Braga, professor da Universidade de São Paulo (USP), corrobora com a ideia da raiz histórica que age diretamente na exclusão social do negro e resulta em precariedade nas condições de vida como moradia, saúde, vida digna em todos os aspectos.

Estar à margem da sociedade e em situação de pobreza, correspondia a uma situação de inadaptação social. A partir de 1970, a exclusão social o conceito exclusão social toma novo rumo e começa a representar o sinônimo da nova pobreza e "uma consequência direta da incapacidade por parte da sociedade em inserir seus membros e não mais como o fruto de uma incapacidade individual em se solidarizar com o todo social" (PAUGAM, 1996, p.60).

\section{A GUISA DE REFLEXÃO}

Os motivos da exclusão social do negro, remeterá a questão social, as novas formas de segregação social que no cenário covid 19, perpassam também pela ausência de tecnologias adequada que permita ao cidadão a comunicação e o acesso ao mundo globalizado, o que não acontece nos quilombos.

As comunidades quilombolas receberam orientação para ficar em casa. Só não perguntaram, quais as condições de sobrevivência dessas pessoas? Como poderão ficar em casa sem a alimentação adequada, sem condições de higiene adequada pela ausência de água potável? Há necessidade de ir até o Lago, afinal, a água é retirada do lago. As condições de 
moradia não permitem que passem tanto tempo no mesmo espaço pelo tamanho de algumas casas e o número de pessoas. Quem fornecerá as máscaras para os contatos indispensáveis?

Perguntas como as do parágrafo anterior, retratam o capitalismo excludente que tornou os negros vulneráveis diante do cenário Covid 19, pela compreensão de que Estado e capitalismo estão estruturalmente relacionados pela falta de visão da realidade do negro, especificamente, das comunidades quilombolas, como povo com pouco ou nenhum valor cultural. Sob poder de soberania dos governantes políticos impermeados na sociedade, o racismo encontra-se institucionalizado e isso gera desigualdade, discriminação e exclusão social em todos os níveis.

\section{REFERÊNCIAS:}

ALMEIDA, Silvio Luiz de. O que é racismo estrutural? Belo Horizonte (MG): Letramento, 2018 .

ALVES, Rubem. 300 Pílulas de Sabedoria. São Paulo: Planeta, 2015.

AZEVEDO, Célia Maria M. de. Onda negra, medo branco: o negro no imaginário das elites - século XIX. Rio de Janeiro: Paz e Terra, 1987.

D’ADESKY, Jacques. Pluralismo étnico e multi-culturalismo: racismos e anti-racismos no Brasil. Rio de Janeiro: Pallas, 2001.

FERNANDES, Florestan. A integração do negro na sociedade de classes. Vol. 1 - O legado da raça branca. São Paulo: Dominus/Editora Universidade de São Paulo, 1965.

FERNANDES, Florestan. A integração do negro na sociedade de classes. Vol. 2 - No limiar de uma nova era. São Paulo: Ática, 1978a.

FIOCRUZ. Organização Mundial da Saúde declara novo coronavírus uma pandemia. Disponível em: $\quad<$ https://www.canalsaude.fiocruz.br/noticias/noticiaAberta/organizacaomundial-da-saude- declara-novo-coronavirus-uma-pandemia11/03/2020.

GUIMARÃES, Antonio Sérgio Alfredo. "Raça", racismo e grupos de cor no Brasil. In: Estudos Afro-asiáticos. n.27, Rio de Janeiro: CEAA, 1995.

HEGEL, G. W. F. (1770-1831). Filosofia do direito. Trad. Paulo Meneses (et.al) São Leopoldo, RS: Ed. Unisinos, 2010.

IBGE - INSTITUTO BRASILEIRO GEOGRÁFICO E ESTATÍSTICO-Mulheres e negros são os mais afetados pela covid-19 no Brasil, pesquisa IBGE 24/07/2020 06h58...

JONES, C. P. Confronting institutionalized racism. Phylon, Atlanta v. 50, n.1, p. 7-22, 2002. 
JORNAL SOCIO AMBIENTAL Pandemia-de-covid-19-expoe-abandono-do-estado-comquilombos https://www.socioambiental.org/pt-br/noticias-socioambiental

LOPES, F.; WERNECK, J. Mulheres jovens negras e vulnerabilidade ao HIV/ Aids: O lugar do Racismo. In: TAQUETTE, S. R. (Org.) Aids e juventude: gênero, classe e raça. Rio de Janeiro: Eduerj, 2009.

MARX, Karl. (1859) Contribuição à critica da economia política. São Paulo: Ed. Martins Fontes, 1984

MBEMBE, Achille. A crítica da Razão Negra. Tradução de Marta Lança. Lisboa: Antígona, 3. ed, 2014.

MUNANGA, Kabengele. Rediscutindo a mestiçagem no Brasil: identidade nacional versus identidade negra. Petrópolis, RJ: Vozes, 1999.

MUNANGA, Kabengele. Uma abordagem conceitual das noções de Raça, Racismo, Identidade e Etnia. $3^{\circ}$ Seminário Nacional Relações Raciais e Educação. PENESB: Rio de Janeiro, 2003. Disponível em: Acessado em: 07/05/2007

PAUGAM, S. L'éxclusion: l'etat dês savoirs. Paris: Seuil, 1996.População negra e Covid19: desigualdades sociais e raciais ainda mais expostas

TEIXEIRA, J. C. As artes e práticas cotidianas de viver, cuidas, resistir e fazer das empregadas domésticas. Universidade Federal de Minas Gerais. Centro de Pós Graduação e Pesquisas em Administração, 2015 